\title{
Spectroscopic and electrical evidence of transition to nanostructured behaviour in $\mathrm{SnO}_{2}$
}

\author{
A. Giberti $i^{1,3}$, V. Guidi $i^{1,2}$, C.Malagú $\dot{u}^{1,2}$ \\ ${ }^{1}$ Department of Physics, University of Ferrara, Italy. \\ ${ }^{2}$ IDASC - Istituto di Acustica e Sensoristica "O. M. Corbino," Italy. \\ malagu@fe.infn.it \\ ${ }^{3}$ MIST E-R Laboratory, Bologna, Italy.
}

\begin{abstract}
:
$\mathrm{SnO}_{2}$ sensors with two different average grain size showed diverse behaviors through electrical and spectroscopic characterizations. In the case of direct current electrical responses, the increase in conductance for the same temperature rise was, on average, about three times larger for larger grained samples. Impedance spectroscopic plots were obtained in dry air and were fitted with the same equivalent circuit for the two granulometries, showing important differences in the fitting parameters. The two techniques present interesting analogies for the same temperature variations. We interpreted this behaviour in terms of barrier modulation through gas chemisorption and oxygen indiffusion, also taking into account of tunneling contribution to conductivity.
\end{abstract}

Key words: Gas Sensors, Impedance Spectroscopy, nanostructures, semiconductors.

\section{Introduction}

An insight into the fundamental mechanisms of double barrier formation at gas-semiconductor interfaces is essential to explain the modified behavior of nanocrystalline $\mathrm{SnO}_{2}$ when the grain radius reaches the threshold of depletion region width [1]. Aim of this work is to justify, through a previously developed model, some experimental evidence which could not be explained with the standard approach.

The authors have proposed an interpretation of conductivity in nano-crystalline semiconductors which includes tunneling contribution through the double Schottky barrier formed at grain-gasgrain interface [2-3].

When the sample is biased, the electron current density from a negatively biased grain to a positively biased grain must be calculated including both thermionic and tunneling contributions as discussed in [3]:

$$
J_{1}=A T^{2} \exp [-(\phi+\xi) / k T]+\frac{A T}{k} \int_{0}^{\phi} F(E) P(E) d E
$$

where $F(E)$ is the Fermi-Dirac distribution and $P(E)$ is the transmission probability which can be calculated by means of the WentzelKramer-Brillouin (WKB) approximation. $E$ is the energy of an electron measured from the conduction band bottom (CBB), $T$ is the absolute temperature, $f$ is the surface barrier height, $\mathrm{z}$ the distance between $\mathrm{CBB}$ and Fermi level $\left(E_{F}\right)$ in the bulk, $A$ the Richardson constant and $k$ the Boltzmann constant. This model allows us to account for the experimental evidence reported in the next section.

\section{Experimental}

Two sets of $\mathrm{SnO}_{2}$ gas sensors, achieved through thick-film technology were prepared. The sensing layers were deposited onto miniaturized laser pre-cut alumina substrates equipped with a heater on the backside, a Pt100 resistor for the control of the sensor operating temperature and golden front interdigitated contacts. $\mathrm{SnO}_{2}$ powders were produced through sol-gel technique [4]. The pastes used for screen-printing are a mixture of nanometric powders, an organic vehicle together with a small percentage of glass frit to improve the adhesion of the layers to the substrates. The thickness of the deposited layers was about $20-30 \mathrm{~mm}$. The films underwent the following thermal treatments: two sets of sensors were annealed at 650 and 850 ${ }^{\circ} \mathrm{C}$, respectively in order to obtain the two morphologies shown in ref [3]. The average grain radius was determined via direct SEM observations and resulted: $150 \mathrm{~nm}$ and $60 \mathrm{~nm}$, respectively. The sensors were placed in a sealed chamber, equipped for flow-through 
technique, whose temperature was kept at 300 $\mathrm{K}$ and $\mathrm{RH} 28 \%$ during the whole set of measurements. Impedance spectroscopic analysis was performed on the two sets of films in dry atmosphere.

\section{Results and discussion}

The two sets of sensors were operated at different working temperatures in order to observe the influence in the variation of conductance. In fact, samples hereinafter labeled (a) have grain radius comparable to the depletion region width $(60 \mathrm{~nm})$, whereas samples labeled (b) have grain radius much larger than it $(150 \mathrm{~nm})$. Therefore, we expect that the nanometric behavior described in previous works [2,3] takes place when the dimensions become comparable to the depletion region width. To this purpose we performed electrical analyses under varying atmosphere and impedance spectroscopy on $\mathrm{SnO}_{2}$ thick-films and observed very different behavior. Anomalous resistance and capacitance variations with gas and temperature were evidenced when the depletion region width becomes of the order of grain radius. As can be seen in Tab.1, the two sensors labeled b), suffer from triple increase of conductance with respect of that of the sensors labeled a) for the same temperature rise.

Tab. 1: Conductance values at different $T(K)$

\begin{tabular}{|c|c|c|}
\hline Conductance & $\begin{array}{c}\text { Average } \\
\text { value for set } \\
\text { (a) }\end{array}$ & $\begin{array}{c}\text { Average } \\
\text { value for set } \\
\text { (b) }\end{array}$ \\
\hline $\mathrm{G}_{300}\left(10^{-10} \mathrm{~S}\right)$ & 3 & 3.7 \\
\hline $\mathrm{G}_{623}\left(10^{-7} \mathrm{~S}\right)$ & 2.6 & 7.6 \\
\hline $\mathrm{G}_{623} / \mathrm{G}_{300}$ & 866 & 2500 \\
\hline
\end{tabular}

The larger increase in conductance shown by larger grained samples can be explained in terms of the model recalled by eq. (1). From the numerical solution of that equation, presented in ref. [3], it is shown that an increase in current is obtained for grains in which the barriers touch at the centre, with respect to grains in which the depletion region is smaller than the grain radius. In other words, as the grain becomes fully depleted free charge cannot be responsible for asymmetric potential drop along positively and negatively polarized grains, and the potential drop is necessarily half in a grain and half in the other one. This effect results in higher current contribution both from tunneling electrons and thermionic emission, and is experimentally confirmed by electrical responses. Therefore, when $\mathrm{T}$ is increased from $300 \mathrm{~K}$ to typical working temperatures (>600K) in oxygen-rich atmosphere, oxygen in-diffusion is favored [5]. The mechanism of in-diffusion results in depletion layer increasing width because of the annihilation of oxygen vacancies. Thereby, when $T$ is increased, the larger grained samples suffer a transition to barriers touching at the centre of grains: this leads to a strong increase in conductivity for the mechanism explained in Ref. [3], whereas smaller grains were already depleted at RT. Thus, small grains increase their conductance only because of the increase of $T$, whereas in larger ones the above described mechanism contributes to increase it more strongly.

Analogous considerations can be drawn from impedance spectroscopic analysis of the samples. In Fig. 1 and 2 we report the ColeCole plots obtained at four working temperatures. It can be noticed that different grained films present very different behavior.

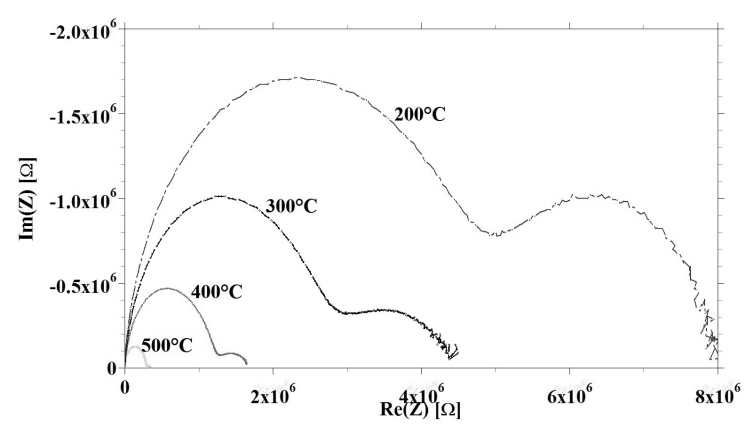

Fig. 1. Cole-Cole plots of sensors of kind (a). Two semicircle are clearly resolved at all working $T$.

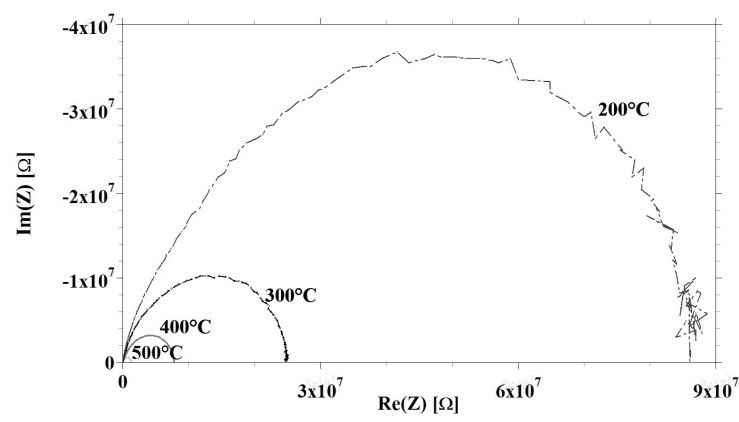

Fig. 2: Cole-Cole plots of sensors of kind (b). Just one depressed semicircle is visible at all working $T$.

The plots were fitted through an equivalent circuit consisting of two $R Q$ in series, $R$ being ideal resistor and $Q$, Constant Phase Element (CPE). The fitting results are presented in tab.2

The two films present different capacitive behavior: the small grained sample a) has two $Q$ elements which strongly differ one another at all working $T$, whereas large grained sample $b$ ) has similar $Q$ values. 
Tab. 2 Fitting circuit parameters for Cole-Cole plots.

\begin{tabular}{|c|c|c|c|c|c|c|}
\hline \multicolumn{7}{|c|}{ Case (a) } \\
\hline $\mathrm{T}\left[{ }^{\circ} \mathrm{C}\right]$ & $\mathrm{R}_{1}[\mathrm{~W}]$ & $\mathrm{Q}_{1}-\mathrm{Y}_{\circ}[\mathrm{F}]$ & $\mathrm{Q}_{1}-\mathrm{n}$ & $\mathrm{R}_{2}[\mathrm{~W}]$ & $\mathrm{Q}_{2}-\mathrm{Y}_{\circ}[\mathrm{F}]$ & $\mathrm{Q}_{2}-\mathrm{n}$ \\
\hline 200 & $3,51 \mathrm{E}+06$ & $9,71 \mathrm{E}-09$ & 0,63 & $\mathbf{4 , 5 9 E + 0 6}$ & $2,59 \mathrm{E}-11$ & 0,8 \\
\hline 300 & $1,41 \mathrm{E}+06$ & $1,30 \mathrm{E}-08$ & 0,62 & $2,01 \mathrm{E}+06$ & $7,25 \mathrm{E}-12$ & 0,9 \\
\hline 400 & $4,79 \mathrm{E}+05$ & $7,34 \mathrm{E}-08$ & 0,56 & $1,14 \mathrm{E}+06$ & $5,77 \mathrm{E}-12$ & 0,92 \\
\hline 500 & $6,26 \mathrm{E}+04$ & $6,72 \mathrm{E}-07$ & 0,45 & $\mathbf{2 , 8 4 E + 0 5}$ & $4,18 \mathrm{E}-12$ & 0,94 \\
\hline \multicolumn{7}{|c|}{ Case (b) } \\
\hline $\mathrm{T}\left[{ }^{\circ} \mathrm{C}\right]$ & $\mathrm{R}_{1}[\mathrm{~W}]$ & $\mathrm{Q}_{1}-\mathrm{Y}_{\circ}[\mathrm{F}]$ & $\mathrm{Q}_{1}-\mathrm{n}$ & $\mathrm{R}_{2}[\mathrm{~W}]$ & $\mathrm{Q}_{2}-\mathrm{Y}_{\circ}[\mathrm{F}]$ & $\mathrm{Q}_{2}-\mathrm{n}$ \\
\hline 200 & $7,20 \mathrm{E}+07$ & $1,24 \mathrm{E}-11$ & 0,95 & $\mathbf{1 , 5 2 E + 0 7}$ & $3,60 \mathrm{E}-11$ & 0,81 \\
\hline 300 & $1,70 \mathrm{E}+07$ & $1,46 \mathrm{E}-11$ & 0,96 & $8,14 \mathrm{E}+06$ & $4,16 \mathrm{E}-11$ & 0,81 \\
\hline 400 & $5,20 \mathrm{E}+06$ & $1,31 \mathrm{E}-11$ & 0,95 & $2,60 \mathrm{E}+06$ & $1,00 \mathrm{E}-10$ & 0,75 \\
\hline 500 & $9,30 \mathrm{E}+05$ & $7,10 \mathrm{E}-12$ & 0,98 & $\mathbf{3 , 8 0 E}+05$ & $2,80 \mathrm{E}-10$ & 0,68 \\
\hline
\end{tabular}

This explains the separation between depressed semicircles in case a) with respect to case b), in which the two semicircles seem not to be resolved. This is also confirmed by the frequency values of the maxima (not reported here), which are very different in case a), and similar in case b).

The bimodal distribution of grains in case a) is, thereby, evidenced by spectroscopic analysis and could not be determined by usual resistive responses. It is worth noticing that the equivalent resistance $R_{2}$ show 2.5 times larger decrease for a DT increase of $300^{\circ} \mathrm{C}$ in case b) with respect to case a). The compared values are highlighted in bold in Tab.2. This result is in very good agreement with the increase of conductance shown in Tab.1, obtained from direct resistance measurements for the same DT. Therefore, the presented model accounts for both kind of measurements. The results also confirm the anomalous behavior reported in Ref.[6], where, in the case of NO injection instead of $\mathrm{CO}$, at the same working temperature, the conductance of a) type sensors strongly decreases because the "touching" barriers at the centre of the grain make the response to the formed $\mathrm{NO}_{2}$ dominant with respect to that to $\mathrm{NO}$.

\section{References}

[1] T.G.G. Maffeıs, G.T. Owen, C. Malagù, G. Martinelli, M.K. Kennedy, F.E. Kruis, S.P. Wilks, Direct evidence of the dependence of surface state density on the size of $\mathrm{SnO}_{2}$ nanoparticles observed by scanning tunnelling spectroscopy, Surface Science 550, 21-25 (2004); doi: 10.1016/j.susc.2003.11.041.

[2] C. Malagù, G. Martinelli, M. A. Ponce, and C. M. Aldao, Unpinning of the Fermi level and tunneling in metal oxide semiconductors, Applied Physics Letters 92, 162104-162107 (2008); doi: 10.1063/1.2916709

[3] C. M. Aldao, D. A. Mirabella, M. A. Ponce, A. Giberti, and $C$. Malagù, Role of intragrain oxygen diffusion in polycrystalline tin oxide conductivity, Journal of Applied Physics 109, 063723 (2011); doi:10.1063/1.3561375

[4] A.Giberti, M. C. Carotta, V. Guidi, C. Malagù, G. Martinelli, M. Piga and B. Vendemiati, Monitoring of ethylene for agro-alimentary applications and compensation of humidity effects, Sensors and Actuators B: Chemical 103, 272-276 (2004); doi:10.1016/j.snb.2004.04.058

[5] Maier, J.,Göpel, W., Investigations of the bulk defect chemistry of polycrystalline Tin(IV) oxide, Journal of Solid State Chemistry 72, 293-302 (1988).

[6] Cesare Malagù, Tunneling through surface barrier and oxygen in-diffusion in nanostructured SnO2 gas sensors, AIP Conference Proceedings 1362, 197-198 (2011); doi: 10.1063/1.3626357 